\title{
Case Report \\ Spontaneous Rupture of Uterine Vein in Twin Pregnancy
}

\author{
Emek Doger, Yigit Cakiroglu, Sule Yildirim Kopuk, Bertan Akar, \\ Eray Caliskan, and Gulseren Yucesoy
}

Department of Obstetrics and Gynecology, Kocaeli University School of Medicine, Kocaeli, Turkey

Correspondence should be addressed to Sule Yildirim Kopuk; suleyildirim@msn.com

Received 28 September 2013; Accepted 1 December 2013

Academic Editors: H. Honnma and S. Jivraj

Copyright (c) 2013 Emek Doger et al. This is an open access article distributed under the Creative Commons Attribution License, which permits unrestricted use, distribution, and reproduction in any medium, provided the original work is properly cited.

\begin{abstract}
Objective. Aim of our study is to present a case of a twin pregnancy following invitro fertilization cycle complicated with hemoperitoneum at third trimester. Case. A 26-year-old nulliparous pregnant woman at 32 weeks of gestation with twin pregnancy following invitro fertilization cycle complained of abdominal pain. After 48 hours of admission, laparotomy was performed with indications of aggravated abdominal pain and decreased hemoglobin levels. Utero-ovarian vein branch rupture was detected on the right posterior side of uterus and bleeding was stopped by suturing the vein. Etiopathogenesis of the present case still remains unclear. Conclusion. Spontaneous rupture of the uterine vessels during pregnancy is a rare complication and may lead to maternal and fetal morbidity and mortality. Diagnosis and treatment are based on the clinical symptoms of acute abdominal pain and laboratory tests of hypovolemic shock signs.
\end{abstract}

\section{Introduction}

Hemoperitoneum in pregnancy is a rare but a dramaticlife threatening complication that results from ruptured uterine vessels [1]. Even though the etiology is poorly understood, sudden rise in venous pressure turning out to vessel rupture and decidualised endometriosis invading vessel wall may be counted as responsible risk factors. In the English literature, approximately 150 cases of rupture of uterine vessels have been reported until now. Brosens et al. stated in their article that bleeding vessels were venous, arterial, or unknown ( $80 \%$, $16 \%$ and $4 \%$, resp.) [2]. Here we present a case of a twin pregnancy complicated with hemoperitoneum following in vitro fertilization cycle (IVF) as a result of utero-ovarian vein branch rupture.

\section{Case}

A 26-year-old nulliparous woman with a dichorionicdiamniotic twin pregnancy achieved by assisted reproductive techniques was admitted at 32 weeks of gestation. At admission, her complaints were epigastric pain and flank pain. Until that time, the patient had an uneventful pregnancy without history of vaginal bleeding, abdominal trauma, uterine contraction, or recent sexual intercourse. Her past medical history included neither abdominal surgery nor myoma uteri. On physical examination, the temperature was $36^{\circ} \mathrm{C}$, the blood pressure was $110 / 70 \mathrm{~mm} \mathrm{Hg}$, the pulse was 92 beats per minute, and respiratory rate was 24 beats per minute and vital parameters were normal. At initial abdominal examination, she had no rebound tenderness. Pelvic examination was one $\mathrm{cm}$ dilated with a soft cervix. Cardiotocography showed irregular contractions with reactive fetal heart rate tracing. Hemoglobin $(\mathrm{Hb})$ was $10.3 \mathrm{~g} / \mathrm{dL}$, hemotocrit level (Hct) was $31.4 \%$, white blood cell count (WBC), C-reactive protein (CRP) level and other laboratory results were normal. Urinalysis revealed $100 \mathrm{mg} / \mathrm{mL}$ protein and leucocyte $(++)$. Obstetrical ultrasonography examination revealed two otherwise healthy fetuses with apppropriate biometrical calculations and with normal amniotic fluid, Doppler flow velocimetry indices. Maternal abdominal ultrasound examination revealed minimal anechoic free fluid in the right lower quadrant but appendix was not observed. Transvaginal ultrasound examination revealed a $26 \mathrm{~mm}$ cervical length.

After hospitalisation, steroid therapy betamethasone (Celestone Chronodose, $1 \mathrm{ml}$, Schering Plough, Germany) was performed for lung maturation. Nifedipine $10 \mathrm{mg} 6$ times a day (Nidilat, Sanofi Aventis, France) and then betaagonists was administered for 24 hours for accelerated uterine 


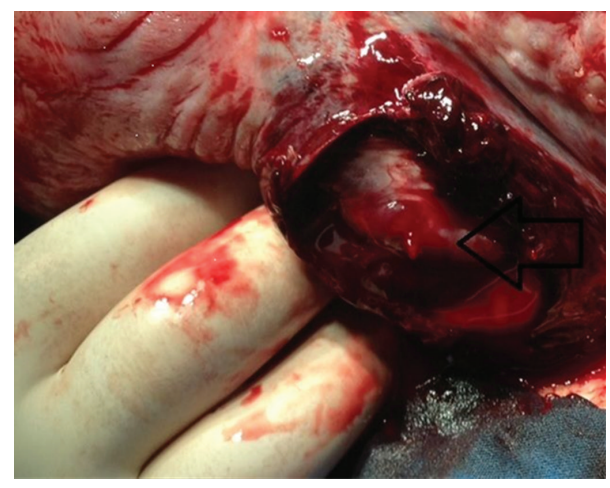

FIGURE 1: Arrow indicates actively bleeding vein.

contractions. Within 24 hours of admission the patient gradually complained of progressive nausea and vomiting. The patient was consulted to general surgery department, and oral intake was stopped, a nasogastric catheter was placed, a proton pump inhibitor was started intravenously, and an antibiotic regimen was administered (ceftriaxone 2 gr/day (Rocephine, Saba, Turkey)) and metronidazole 1 gr/day (Flagyl, Ecz.Baxter, Turkey) for suspicion of appendicitis. Whole abdominal and pelvic magnetic resonance (MR) imagings were performed and revealed a minimal intra-abdominal free fluid without any pathological signs. On the second day, abdominal pain with nausea and vomiting gradually increased but no rebound tenderness was experienced. $\mathrm{Hg}$ level decreased to $9.53 \mathrm{~g} / \mathrm{dL}$, htc level decreased to $29.4 \%$, and WBC increased in value of $19.4 \times 10^{3} / \mathrm{UL}$. Since leucocyte counts increased gradually and symptoms became more obscure, surgery had been decided with the diagnosis of acute abdomen. Under spinal anesthesia, laparotomy was extended through pfannenstiel incision and 300-400 mL hemoperitoneum was observed in the peritoneal cavity. Pelvic exploration revealed blurish color on the posterior right side of the uterus, active bleeding from right uterine vessel, and a torn uterine serosa (Figure 1). A 8-9 apgar, $1760 \mathrm{gr}$, female fetus and a 8-9 apgar, $1730 \mathrm{gr}$, male fetus were born by a Cesarean section. The placenta was normal in appearance without retroplacental hematoma, ablation, or previa. Uterine vein branch was sutured with polyglactin 910 number 1.0. (Ethicon,Johnson \& Johnson) (Figure 2). Postoperative period was uneventful without any necessity of blood transfusion, and the patient was discharged home on the second postoperative day.

\section{Discussion}

In 1950, the largest published series, a review of 75 cases due to utero-ovarian vessel rupture, reported a $49 \%$ of maternal mortality; however mortality rate declined to $3.6 \%$ by subsequent developments in medicine $[1,3]$. Even though hemoperitoneum caused by utero-ovarian vessels rupture may occur in all trimesters, it mostly occurs in the third trimester; $61 \%$ occurred before labour, $18 \%$ was intrapartum, and $21 \%$ was in the puerperal period [3, 4]. Suggested etiologic factors are dilated utero-ovarian veins which have

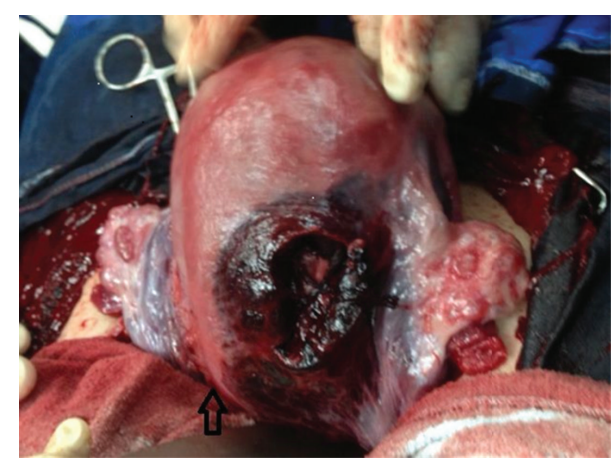

FIgURE 2: Artery was sutured with Vicryl 1.0. Arrow indicates incision side of the uterus.

tortuous nature, lack of valves, increasing physiological demands of pregnancy, and muscular activities such as coughing, defecation, coitus, or pushing phase of secondstage labor that may cause sudden rise in venous pressure being predisposed to spontaneous rupture [5].

Sudden onset of abdominal pain, hypovolemic shock signs, and decreased hemoglobin levels indicate uteroovarian vessels rupture such as other intra-abdominal bleeding causes. Amount, rapidity of blood loss and location of bleeding changes symptoms of hemoperitoneum [6]. Therefore the diagnosis of hemoperitoneum is so difficult before surgery. O'Connel and Pendiville reported a case with Cesarean section prompted by fetal distress with the lack of hemodynamic instability despite 1.51 liter hemoperitoneum [7]. Brosens et al. reviewed 25 cases of spontaneous hemoperitoneum in 12 publications and noted that $72 \%$ of spontaneous hemoperitoneum cases were nulliparous, with a mean age of 30 , and also in all cases abdominal ultrasound examination failed to diagnose intraperitoneal bleeding [2]. Differential diagnosis cited uterine rupture, placental abruption, bleeding ectopic decidua, HELLP syndrome, splenic and hepatic artery aneurysm rupture, and perforated appendicitis.

In the English literature, until now there has been six reported twin cases of hemoperitoneum with stage IV endometriosis and one case with stage I endometriosis [813]. Chronic inflammation due to endometriosis which is influenced by progesterone is reported [14]. Decidualized endometriosis results in more fragile, vulnerable uteroovarian vessels.

We present the fifth twin pregnancy following IVF treatment. Twin pregnancy incidence is increasing which may be due to frequent use of assisted reproductive technologies and has higher rates of obstetrical complications compared with single pregnancies. Therefore similar complications may increase. For the present case, the mechanism of rupture was indefinable, because of lack of endometriosis, adhesions, prior surgery, and myoma uteri. We do not know whether or not during ovum pickup procedure, damaged vessel wall or uterus was prone to rupture as a consequence of hemodynamic alterations of pregnancy such as increased cardiac output. However 3rd trimester ruptured vessel due to 
ovum pickup as a long term complication was not reported in the literature.

The preoperative diagnosis was so difficult because the patient had normal hemodynamic parameters and had a variety of clinical symptoms. Hemoglobin levels did not decrease rapidly which may be due to uterine pressure on the uterine vessel. When acute abdomen is diagnosed, hemoperitoneum should be considered in the differential diagnosis during gestation [15]. Nonspecific symptoms such as acute abdominal pain, vomiting, and maternal acute anemia are signals of hemoperitenoum that should be kept in mind. Close monitoring, instant diagnosis, and intervention should be done.

In conclusion, spontaneous uterine vessel rupture is a rare dramatic event in pregnancy. In a case presenting with severe abdominal pain with either fetal distress or maternal hemodynamic instability, spontaneous uterine venous rupture should be considered. Close observation and early intervention were essential for maternal and fetal survival.

\section{Conflict of Interests}

The authors declare that there is no conflict of interests.

\section{References}

[1] C. P. Hodgkinson and R. C. Christensen, "Hemorrhage from ruptured utero-ovarian veins during pregnancy; report of 3 cases and review of the literature," American Journal of Obstetrics and Gynecology, vol. 59, no. 5, pp. 1112-1117, 1950.

[2] I. A. Brosens, L. Fusi, and J. J. Brosens, "Endometriosis is a risk factor for spontaneous hemoperitoneum during pregnancy," Fertility and Sterility, vol. 92, no. 4, pp. 1243-1245, 2009.

[3] K. A. Ginsburg, C. Valdes, and G. Schnider, "Spontaneous utero-ovarian vessel rupture during pregnancy: three case reports and a review of the literature," Obstetrics \& Gynecology, vol. 69, no. 3, pp. 474-476, 1987.

[4] V. Ziereisen, B. Bellens, C. Gérard, and L. Baeyens, "Spontaneous rupture of utero-ovarian vessels in postpartal period: a case report and review of the literature," Journal de Gynecologie Obstetrique et Biologie de la Reproduction, vol. 32, no. 1, pp. 5154, 2003.

[5] U. Aziz, A. Kulkarni, D. Lazic, and J. E. Cullimore, "Spontaneous rupture of the uterine vessels in pregnancy," Obstetrics \& Gynecology, vol. 103, no. 5, pp. 1089-1091, 2004.

[6] A. J. Jurishica and M. Gutglass, "Bleeding from utero-ovarian vessels," Obstetrics \& Gynecology, vol. 6, pp. 315-319, 1955.

[7] M. P. O'Connell and W. Prendiville, "Spontaneous uterine artery rupture: a rare cause of abdominal pain in pregnancy," Journal of Obstetrics and Gynaecology, vol. 25, no. 5, pp. 511-512, 2005.

[8] M. Roche, M. Ibarrola, N. Lamberto, C. Larrañaga, and M. A. Garcia, "Spontaneous hemoperitoneum in a twin pregnancy complicated by endometriosis," Journal of Maternal-Fetal and Neonatal Medicine, vol. 21, no. 12, pp. 924-926, 2008.

[9] E. Katorza, D. Soriano, D. Stockheim et al., "Severe intraabdominal bleeding caused by endometriotic lesions during the third trimester of pregnancy," American Journal of Obstetrics and Gynecology, vol. 197, no. 5, pp. 501-e1, 2007.

[10] C.-Y. Wu, J.-L. Hwang, Y.-H. Lin, B.-C. Hsieh, K.-M. Seow, and L.-W. Huang, "Spontaneous hemoperitoneum in pregnancy from a ruptured superficial uterine vessel," Taiwanese Journal of Obstetrics and Gynecology, vol. 46, no. 1, pp. 77-80, 2007.

[11] F. Passos, C. Calhaz-Jorge, and L. M. Graça, "Endometriosis is a possible risk factor for spontaneous hemoperitoneum in the third trimester of pregnancy," Fertility and Sterility, vol. 89, no. 1, pp. 251-252, 2008.

[12] M. P. Andrés-Orós, L. Server-De Castro, V. Roy-Ramos, and A. Vela-Lete, "Spontaneous uterine venous rupture during pregnancy. Description of two cases and bibliographical review," Ginecologia y Obstetricia de Mexico, vol. 78, no. 2, pp. 128-131, 2010.

[13] M. Berisavac, R. Sparić, M. Pervulov et al., "Spontaneous intraabdominal bleeding in twin pregnancy: case report," Srpski Arhiv Za Celokupno Lekarstvo, vol. 136, no. 5-6, pp. 299-301, 2008.

[14] T. Inoue, T. Moriwaki, and I. Niki, "Endometriosis and spontaneous rupture of utero-ovarian vessels during pregnancy," The Lancet, vol. 340, no. 8813, pp. 240-241, 1992.

[15] Y. Nakaya, H. Itoh, K. Muramatsu et al., "A case of spontaneous rupture of a uterine superficial varicose vein in midgestation," Journal of Obstetrics and Gynaecology Research, vol. 37, no. 8, pp. 1149-1153, 2011. 


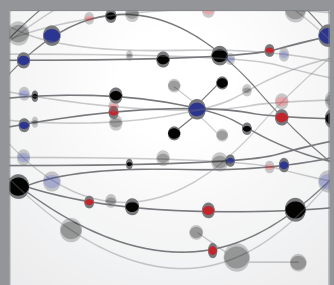

The Scientific World Journal
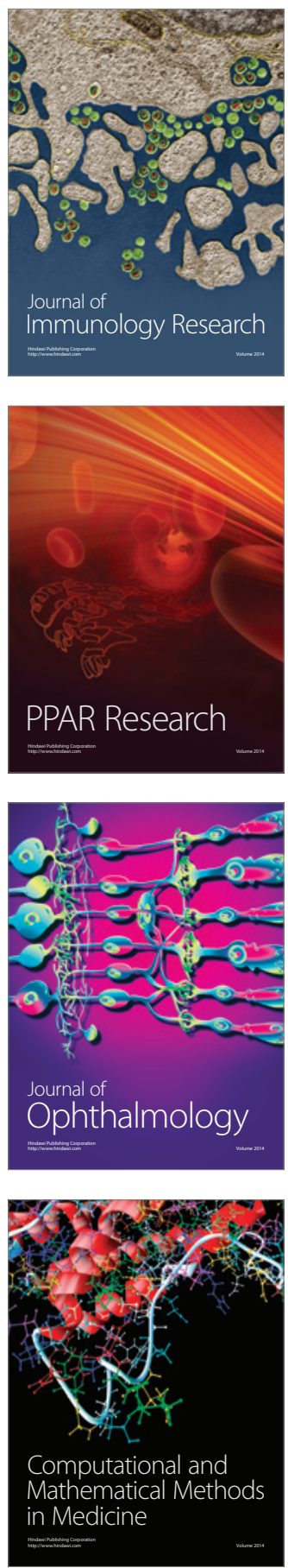

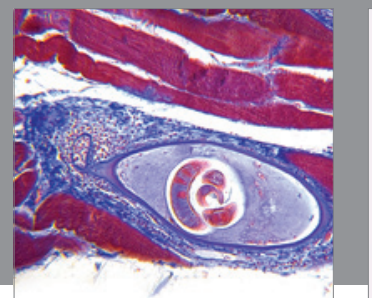

Gastroenterology

Research and Practice
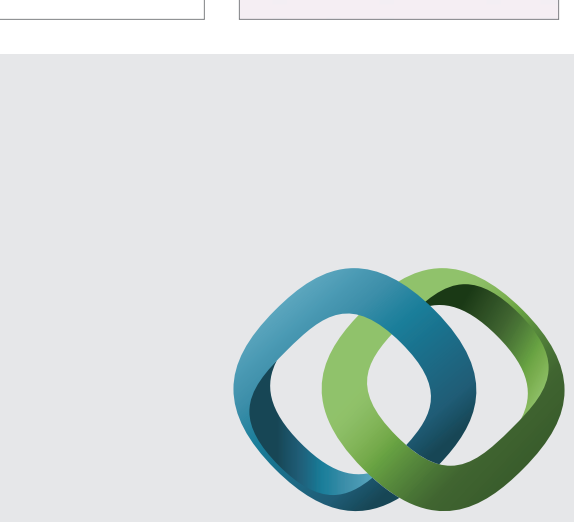

\section{Hindawi}

Submit your manuscripts at

http://www.hindawi.com
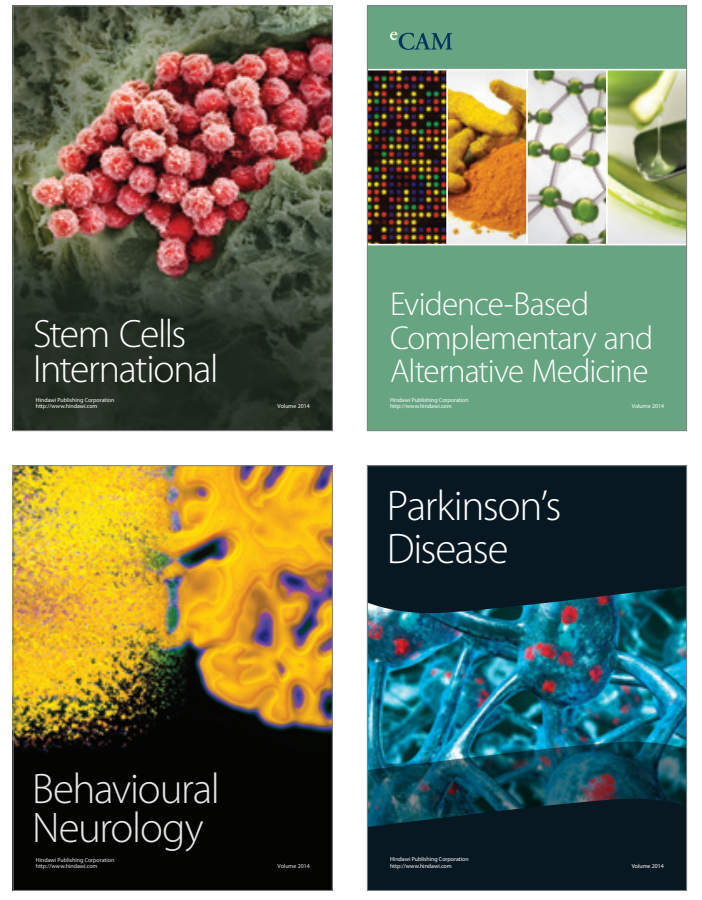
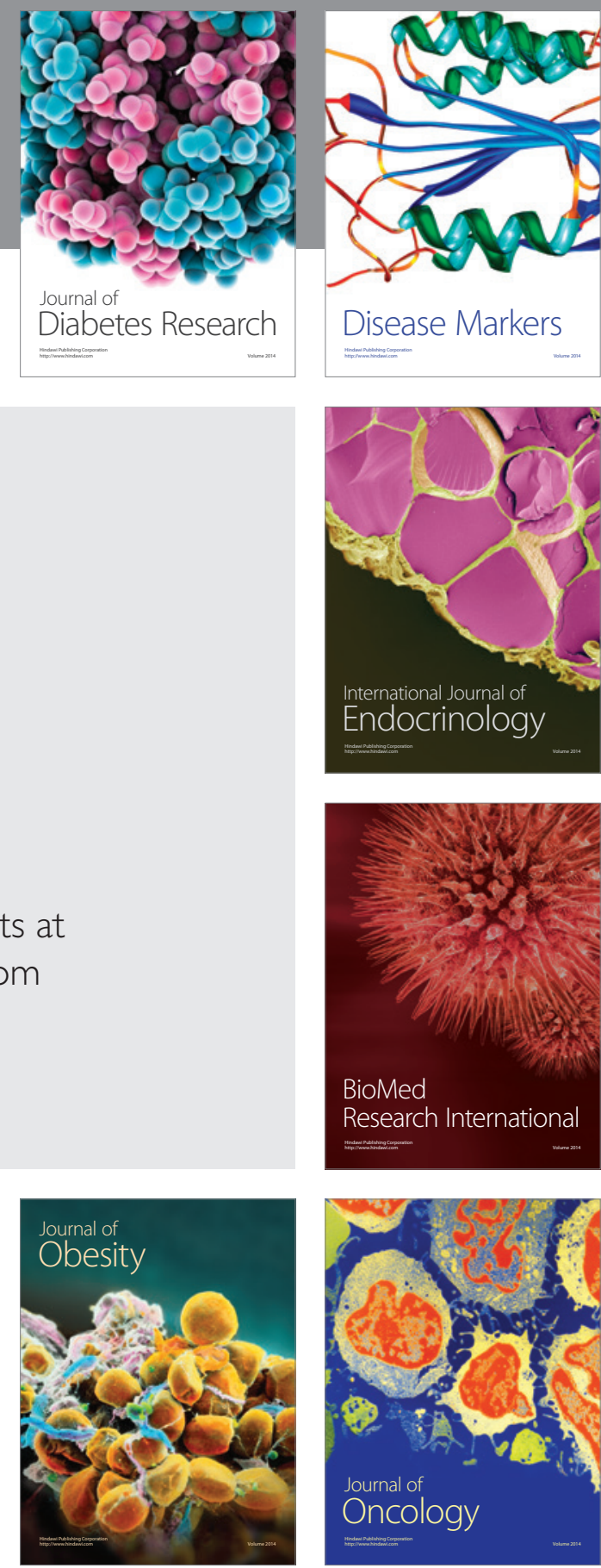

Disease Markers
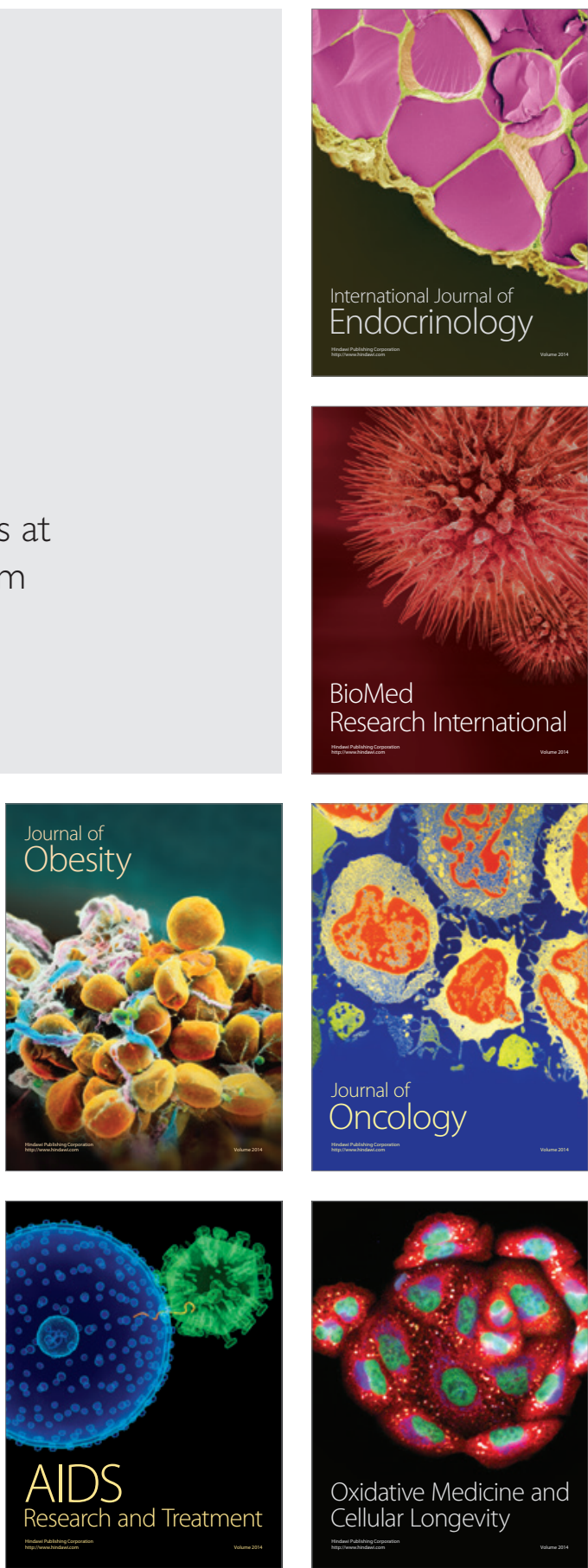